\title{
Limits of Hybrid Modal Realism
}

\author{
Maciej Sendłak
}

Received: 1 July 2014 / Accepted: 18 December 2014/Published online: 30 December 2014

(C) The Author(s) 2014. This article is published with open access at Springerlink.com

\begin{abstract}
The aim of this paper is to point out the limitations of Hybrid Modal Realism as a general theory of modalities, i.e. one that gives an analysis of possibilities as well as impossibilities. To do so we will firstly sketch the goals that theories of impossible worlds should achieve. Secondly we will briefly present the two most popular accounts of impossibilities-Extended Modal Realism and Extended Ersatzism. We will focus on the aspects of both theories which became the motivation for a hybrid view. In the last part of this paper we will analyze Francesco Berto's Hybrid Modal Realism and present reasons why this account is an insufficient tool for analyzing impossibilities.
\end{abstract}

Keywords Impossible worlds · Counterpossibles · Constructed worlds · Metaphysics of impossibility

\section{Introduction}

Over the last two decades, interest in the analysis of impossibilities has been growing slowly but constantly. Philosophers working on this issue have argued that a framework of exclusively possible worlds is insufficient for delivering a proper analysis of modalities in general. Although the reasons for introducing impossible worlds are-as we will see-interesting and well-motivated, a difficulty exists concerning the nature of such entities. ${ }^{1}$ Two well-known positions in the debate

\footnotetext{
M. Sendłak $(\bowtie)$

Department of Philosophy, University of Szczecin, Szczecin, Poland

e-mail: maciej.sendlak@gmail.com

M. Sendłak

Graduate Center, CUNY, New York, NY, USA
}

${ }^{1}$ For a detailed presentation of theories of impossible worlds see (Berto 2013; Nolan 2013). 
over the nature of impossible worlds are (as in the case of possible worlds) concretism and abstractionism. Concretism is usually regarded as highly controversial, while abstractionism is often considered ontologically cheaper but theoretically less attractive. As a result of this difficulty, a new hybrid view has been developed, according to which possible worlds are spatiotemporal objects, while impossible worlds should be considered abstract constructions of possible worlds. Since the idea and the motivation behind the hybrid view are interesting, it is worth examining this account from the perspective of the aims of the analysis of impossibilities.

\section{Work for Impossible Worlds}

Many philosophers agree that the actual world could be different in many ways, and for each of these ways there is at least one world which in some sense represents or exemplifies it. In other words, for every possibility, there is at least one world which represents it. Thanks to this, we can easily distinguish merely possible (i.e., possible, but not actual) objects, such as a "winged horse" or a "blue giraffe." Because both of these are logically possible, they are represented by different objects which are elements of non-actual worlds. ${ }^{2}$ Depending on the given account of possibilities, they are taken to be non-actual spatiotemporal objects or actually existing abstract objects. Although there is a long-standing debate over the ontological nature of a non-actual world, most philosophers argue that worlds must be logically possible, i.e. consistent and maximal. This view is expressed by the claim that, (1) for every possible world $w$ and for every proposition $\mathrm{P}$, it is the case that either $\mathrm{P}$ at $w$ or $\neg \mathrm{P}$ at $w$, and (2) for any $\mathrm{P}$ and for any $w$ it is not the case that $\mathrm{P} \& \neg \mathrm{P}$ at $w$. The consequence of these criteria is that there are no incomplete or inconsistent worlds.

This claim, although commonly accepted, leads to an important limitation of theories of modalities: specifically, that there are no worlds which represent incomplete or inconsistent objects. This leaves us unable to distinguish between objects that we might label as logically impossible. Some may say that there are no such things as impossible objects, because each object is by definition possible. If one is committed to an only-possible-objects ontology, then surely this is so. Nevertheless, our analysis should show reasons for finding a place in the domain of objects for impossible ones as well. In this sense we are using a broader notion of an object, i.e., one which might be called Meinongian. Thus, such logically impossible entities as a round square or a married bachelor are objects as well. From a logical point of view regarding the actual world, there is no (possible) world where any of these things exists. In this sense, a (logically) impossible object is an object which does not exist in any (logically) possible worlds.

\footnotetext{
2 As we shall see, since we can distinguish various types of possibilities (logical, theoretical, physical, mathematical, biological etc.) it is difficult to talk about "possible" tout court. Although we will focus now on logical possibilities, in each succeeding case we will mark what kind of possibility or impossibility we are dealing with.
} 
It is worth contrasting logically impossible objects with other types of impossibility. For instance, we can postulate nomologically impossible objects. These are objects whose existence contradicts what we take to be necessarily true according to the laws of actual worlds. An example of this might be an object which travels faster than speed of light. Although this is (according to contemporary theories of physics) physically impossible, it does not mean that there are no logically possible worlds where it is possible. After all, science fiction authors have written books on this idea, and we consider them to be describing at least a logically possible situation (Priest 1992: 292). In fact, as long as such ideas are logically possible, there is a logically possible world in which they exist. We can say the same about legal or biological impossibilities. According to law in the actual world, it is impossible to be the president of the USA and at the same time not to be a citizen of the USA. This means that in all legally possible worlds, i.e., worlds where the laws are the same as in the actual world, every president of the USA is also a citizen of the USA. Nevertheless there are also logically possible worlds where the president of the USA holds a different citizenship. These are legally impossible worlds. In this sense there is a plentitude of impossibilities which can be analyzed in terms of logically possible worlds. As we see, the term "impossible" can be used in different contexts, but what they share is that something is impossible according to what is taken to be true in the actual world.

The analysis of nomological impossibilities (as long as they are logically possible) seems not to be a troublemaker for advocates of only-possible-worlds accounts. After all, they can always point to a possible world which represents the given legal, biological or physical impossibilities. This is because theorists of modality rarely make any radical claims about the truth of a given theory of law, physics or biology, since such claims would be irrelevant from the point of view of the philosophy of modalities. They are important for theorists of law, physics and biology, but not especially so for logicians and metaphysicians. On the other hand, many philosophers are clear about what kind of logic, mathematics or metaphysics is true, and although they differ as to details, one claim is commonly accepted. This is the rule of necessitation, stating that if a theorem (A) of a given theory is true, then it is necessarily true ( $\square \mathrm{A})$, i.e. true in all possible worlds $(\vdash \mathrm{A} \rightarrow \square \mathrm{A})$. That means that if a given kind of metaphysics, logic, or mathematics is true in the actual world, then there is no possible world where it is untrue.

This enables us to introduce new types of impossibility, which we will call, respectively, mathematical and theoretical. ${ }^{3}$ An example of the former is the largest prime number. An example of the latter is any entity whose existence contradicts the claims of a given kind of metaphysics. Naturally, some theoretical or mathematical impossibilities are also logical impossibilities, e.g. a round square. It should be stressed that there is no need to be parity between theoretical and logical possibilities. After all, there are many logicians with no interest in metaphysics. Because of this, from a merely logical point of view various accounts of metaphysics might be truein fact, any which do not contradict a given logic. Nevertheless the subject of this

\footnotetext{
${ }^{3}$ We will use the term "theoretical impossibilities" for what is impossible from the point of view of a given theory of metaphysics.
} 
paper is one account of the metaphysics of impossibilities, and as such we will treat theoretical and logical impossibilities as equally important.

Unfortunately, by relying on only possible worlds, one cannot identify a condition for discriminating among logical, metaphysical or mathematical impossibilities. After all (according to the rule of necessitation), there are no worlds where they exist. In order to do so one must postulate worlds which contain certain impossible objects, i.e., worlds where, for example, a round square or a married bachelor or the highest natural number exists. Obviously, such worlds cannot be part of any of possible worlds, since that would contradicts the rule of necessitation. Thus, if we wish to distinguish between these impossible objects, we must claim that they are parts of impossible worlds.

Although we are focusing here on impossible objects, which correspond to names, what we have said also applies to propositions, expressed by sentences. Let us recall that, according to standard analysis, sentences which express possibility, such as "The Netherlands will win the World Cup in 2018," correspond to propositions which obtain in some possible worlds. But again, not every sentence expresses possibility. There are plenty of examples of situations that cannot happen. The most obvious are those which can be represented by simple insertions of conjunctions between contradictory sentences, such as:

1. It is raining and it is not raining at the same time.

2. It is snowing and it is not snowing at the same time.

Unless one is a dialetheist, there is no reason to believe that either (1) or (2) describes something that could happen. In this sense it is easy to say that there are no possible worlds where the above sentences are true, because each of them is a necessarily false claim. Impossibilities of this kind are sometimes called blatant (Lewis 2004). Besides these, one can also mention subtle impossibilities, i.e. those which are necessarily false, but which are not contradictions per se. In this category, we can place such mathematical impossibilities as:

3. 10 is a prime number.

4. The largest natural number exists.

along with theoretical impossibilities:

5. The Monadology is true.

6. There is an individual who exists entirely in two different worlds.

As mentioned earlier, by theoretical impossibilities we mean propositions expressed by sentences which from the point of view of a given theory are necessarily false. If we assume, for example, that Lewis's modal realism is true, then obviously sentences (5) and (6) should be taken as expressing impossibilities. This is because there is no world where (5) or (6) is true. Otherwise, the truth of either of these 
claims would imply the falsehood of Lewis's modal realism. The latter can be taken as necessarily true according to abstractionist accounts, but for the same reason, for these types of theories, the claim "spatiotemporal non-actual worlds exist" will be necessarily false.

Thus, when we talk about impossibility, it should be taken as indexical. This means that no proposition is impossible in an absolute sense. Just as every proposition is possible with respect to what is assumed to be necessarily true, so is every impossibility. In this sense, although true contradictions are impossible from the point of view of classical logic, they are possible from that of paraconsistent logics. ${ }^{4}$ Similarly as in the case of impossible objects, since sentences (1)-(6) are necessarily false, there are no possible worlds where they are true. In other words, one of the main claims of the advocates of impossible worlds is that, just as for every possibility there is a world which represents it, similarly, for every impossibility, there should be a world which represents this impossibility (Yagisawa 1988; Nolan 1997; Mares 1997).

The difficulties of representing impossibilities in the classical approach to modalities also have consequences for the interpretation of counterfactuals, i.e., sentences of the form "If $\varphi$, then $\psi$ (symbolically " $\varphi>\psi$ "), " where it is stated that a possible fact $\varphi$ leads to a consequence $\psi$. For instance, "If it were the case that all icebergs around the North Pole melted, then it would be the case that the level of the oceanic water would be higher", "If it were the case that Kant lived in London, then it would have been the case that he wrote his books in Spanish."

Let us recall that according to the well-known Stalnaker-Lewis (S-L) analysis of counterfactuals:

" $\varphi>\psi$ " is true in the actual world (@) iff either (1) $\varphi$ is impossible (necessarily false) or (2) every world $w_{1}$ where $\varphi$ and $\psi$ are true is more similar to the actual world than any world $w_{2}$, where $\varphi$ is true and $\psi$ is false. ${ }^{5}$

Thanks to the possible-worlds analysis of counterfactuals, we can explain why some of the sentences mentioned above are true or false. We take the counterfactual "If it were the case that all icebergs around the North Pole melted, then it would be the case that the level of the oceanic water would be higher" to be true, because worlds where the antecedent and the consequent are both true is more similar to the actual world than a world in which, although all icebergs around the North Pole have melted, the level of the water in the ocean is not higher. On the other hand, we take the sentence "If it were the case that Kant lived in London, then it would have

\footnotetext{
${ }^{4}$ Unless indicated differently, we will assume for the sake of argument that classical logic and modal realism are true in the actual world and thus are true in every possible world as well.

5 See (Stalnaker 1968; Lewis 1973). It should be stressed that, contrary to Stalnaker's account, for Lewis there need not be a unique closest world. Although one can easily find some differences between these theories, they are not significant from the point of view of this article. The most important fact is that both are expressed in terms of possible worlds. Moreover, although in an elaborated view Lewis claimed that worlds are concrete spatiotemporal and isolated objects (Lewis 1986), (S-L) is neutral about the nature of possible worlds. In this sense, one can accept $(\mathrm{S}-\mathrm{L})$ without accepting modal realism. This enables the interpretation of worlds as a maximal and classically consistent set of sentences of a given formal language $\mathrm{L}$.
} 
been the case that he would have written his books in Spanish" to be false, because a world where the antecedent as well as the consequent of this counterfactual are true is less similar to the actual world than a world in which Kant lived in London and did not write his books in Spanish, but in English.

The S-L account offers an elegant theory of "typical" counterfactuals. Now let us take a look at some special types of counterfactuals, called counterpossibles. These are counterfactuals with impossible (necessarily false) antecedents. The simplest examples of such antecedents are logical contradictions:

7. If it were raining and not raining at the same time, then Berlin would be the capital of Argentina.

8. If it were raining and not raining at the same time, then Berlin would be the capital of Germany.

Both of these counterfactuals contain impossible antecedents and thus both (7) and (8) are, according to the S-L account, true regardless of the truth-values of their consequents. In this sense, all counterpossibles are vacuously true.

As we mentioned earlier, impossibilities encompass more than just simple contradictions. Each well-formed sentence which is necessarily false should be taken as expressing an impossibility. Even if what a sentence expresses is logically possible, it can be taken to be impossible from the point of view of a given kind of metaphysics or mathematics. Accordingly, we may distinguish more interesting kinds of counterpossibles:

9. If monads existed, then Leibniz would be right about metaphysics.

10. If monads existed, then Leibniz would be wrong about metaphysics.

From the point of view of modal realism it is impossible for monadology to be true, since, if a given account of metaphysics (modal realism, in our example) is true, it must be necessarily true. Thus sentences (9) and (10) have theoretically impossible antecedents, which, according to condition (1) of S-L, require us to state that both of them are true. On the other hand, anyone familiar with the history of philosophy would say that (9) is non-vacuously true while (10) is false. A similar example might be given for mathematical counterpossibles:

11. If Hobbes had squared the circle, then mathematicians would be impressed.

12. If Hobbes had squared the circle, then mathematicians would not be impressed.

Regardless of impossible antecedents, in both cases we can point out non-vacuously true and non-vacuously false sentences. Moreover, we often use them when reasoning about certain counterfactual situations. Thus, it is justified to take the problem of counterfactuals with impossible antecedents to be a serious issue requiring a more sensitive theory, i.e. one that would not take all of them to be vacuously true. 
The third limitation of the only-possible-worlds analysis is, in some sense, connected with the previously mentioned problem of counterpossibles. Since classical logic is not the only kind of logic, we can also say something true or false about inferences in non-classical logics, such as paraconsistent or intuitionist. We can identify the consequences of accepting each of these logics. According to valid inferences based on the apparatus of these frameworks, we can point out the nontrivial consequences of such decisions. Even if one argues against each of them, one should point out the unwelcome or controversial consequences of accepting a given formal system. The reasoning will be valid only if one assumes the adequacy of a given account. Consider two counterpossibles:

13. If paraconsistent logic were correct, then ex contradictione quodlibet would be false.

14. If paraconsistent logic were correct, then ex contradictione quodlibet would be true.

Obviously, if classical logic is necessarily true (which is our basic assumption), then it is impossible for paraconsistent logic to be correct. And once again, according to S-L, we have to admit that (13) as well as (14) are vacuously true, even if we would prefer to say that (14) is false. Although we assume the truth of classical logic here, the case might easily change depending on what we believe to be necessarily true.

We can give similar examples involving alternative accounts of metaphysics. Since reasoning within someone else's metaphysics requires one to assume that there is a world where a given alternative metaphysical account is true, and since, according to theories accepted by the critics, it is impossible that the alternative account is true, one should assume that such an account can be true only in an impossible world.

In general it is true that if one adopts S-L, and a particular account of, for example, metaphysics, logics or mathematics, then one cannot base non-vacuously true reasoning on the truth of an alternative view, respectively, on metaphysics, logics or mathematics. This is because for every theory, if a thesis of this theory is true, then the theory itself is necessarily true.

It is easy to see that the issues mentioned above are closely connected and that each of them stems from the limitations of only-possible-worlds theories. In order to solve these puzzles, some philosophers have argued for the extension of ontology to worlds where what is considered impossible/necessarily false in the actual world is true. In other words, to deal with the above puzzles one should postulate not only the existence of logically, theoretically and mathematically possible worlds, but also worlds which are impossible according to the logic, metaphysics or mathematics of the actual world.

One of the puzzling issues characterizing this approach is the question of the metaphysical nature of these entities. Since theories of impossibilities should be extensions of classical theories of modalities, many philosophers ascribe the same nature to possible worlds as to impossible worlds. This is sometimes called the parity thesis. As we will see, not all philosophers accept this principle. ${ }^{6}$

\footnotetext{
${ }^{6}$ For discussion on the parity thesis see (Priest 1997; Brandom and Rescher 1980; Kiourti 2010).
} 


\section{Metaphysics of Impossible Worlds}

As in the debate on the metaphysical nature of possible worlds, one can divide the advocates of impossible worlds into two groups: concretists and abstractionists. A well-known concretist account of impossible worlds is Extended Modal Realism (EMR), represented by Takashi Yagisawa (1988). EMR is based on Modal Realism and is probably the most controversial account of impossible worlds. The main claim of EMR is that possible and impossible worlds have the same ontological nature: they are spatiotemporal objects. Just as every possible situation can be found in some possible worlds, every impossible situation can be found in some impossible worlds. In this sense, there are spatiotemporal worlds where it is raining and not raining at the same time, where a round square or the largest prime number exists, and so on. Since such worlds are not logically possible, they surely cannot be a part of the space of classical logic. Therefore, Yagisawa postulated the existence of a plentitude of logical spaces, which are sets of worlds similar to each other in a given aspect. As such, each world which is ruled by a given logic $L_{1}$ belongs to $L_{1}$ logical space. For example, a non-trivial world where a contradiction is true is a world which belongs to the space of paraconsistent logic. In this sense, claims Yagisawa, one can believe in the existence of a round square and at the same time assume that the actual world is ruled by classical logic. ${ }^{7}$ After all, it is impossible for a round square to exist. Because of that, it exists in an impossible world-which the actual world is not. As a result, we have a theory according to which impossible worlds have the same nature as possible ones. They are concrete mereological sums of individuals, causally and spatiotemporally isolated from each other. To extend Lewis's claim: quantification of different ways the world could not be should be taken at face value and used as a reason to admit real impossible worlds. ${ }^{8}$

Regardless of the severe ontological cost of Yagisawa's account, this kind of extension seems to satisfy the aims of the introduction of impossible worlds. First of all, since every impossibility is realized in one of the impossible worlds, one can distinguish between various examples of impossibilities. In this sense the words "round square" and "largest natural number" have different extensions: the referents of these words are parts of different worlds.

Consequently, one can also deal with counterpossibles and models for alternative logics and metaphysics. To do so, it suffices to extend S-L (to ES-L) analysis so that it contains (logically or theoretically) possible as well as impossible worlds:

\footnotetext{
7 As we shall see, in fact, according to EMR, one cannot accept both of these claims.

${ }^{8}$ One might doubt whether introducing a new kind of metaphysics helps in the analysis of impossibilities at all. After all, for every theory of impossibilities $T_{1}$ we can ask how to represent the impossibility that $T_{1}$ is false. Every account has to assume the truth of given premises to be non-trivial, and analysis of this kind of impossibilities require rejecting it. This problem infects any account of the metaphysics of impossibility and as such might call into question the postulation of impossible worlds in the first place (Sendłak 2015).

Since our aim in the present paper is to compare one of theories of impossible worlds (Hybrid Modal Realism) with theories which serve as alternatives, we will suspend the above-mentioned doubt. For the sake of argument we will focus on those aspects of these theories which are independent of this problem. We are aware that this might fail to satisfy those readers who wish to investigate the problem that we raise in this footnote; nevertheless, the problem should not influence our analysis of Hybrid Modal Realism.
} 
" $\varphi>\psi$ " is true in the actual world (@) iff every (possible or impossible) world $w_{1}$ where $\varphi$ and $\psi$ are true is more similar to the actual world than any world $w_{2}$, where $\varphi$ is true and $\psi$ is false

According to this analysis, counterpossibles (9) and (11) should be considered true, since the impossible worlds where their antecedents and consequents are true are closer (more similar) to the actual world than worlds where the consequents of these counterfactuals are false and the antecedents true. The case of models for nonclassical logic and alternative metaphysics is similar. There are worlds which are parts of non-classical logical spaces where, for example, paraconsistent logic is true, and thus one can draw non-trivial inferences based on the axioms and rules of this logical system.

Yagisawa took modal realism as the basis of his theory and emphasized the theoretical advantages of this account, such as extensional analysis of predicates and propositions. Unfortunately, postulating spatiotemporal impossible worlds results in some problems in the general analysis of modality. First of all, the ontological price is too high. Real impossibilities take this account further from what most modal realists would like to admit, mostly because even if one wishes to claim that contradictions are true only in some impossible worlds, this would also imply a contradiction in the actual world, because of Lewis's analysis of truth conditions, according to which, from the actual world's point of view:

$\varphi$ is true at possible world $w_{1}$ iff at $w_{1}: \varphi$

$\neg \varphi$ is true at possible world $w_{1}$ iff $\neg\left(\right.$ at $\left.w_{1}: \varphi\right)$

If one postulates an impossible world $w_{1}$ where $\varphi$ and $\neg \varphi$ are true $(\varphi \& \neg \varphi)$, then one has to claim that from the actual world's point of view it is true that:

$$
\text { (at } \left.w_{1}: \varphi\right) \& \neg\left(\text { at } w_{1}: \varphi\right)
$$

In this sense, a true impossibility in a non-actual world might lead to a contradiction in the actual world (Lewis 1986: 7, note 3).

Secondly, the introduction of real impossible worlds deprives Lewis's theory of one of its major advantages, which is a reductive analysis of modality. Let us recall that according to his modal realism, sentences with modal terms are reduced to supposedly clearer claims of spatiotemporal objects (worlds):

(MR) It is possible that $\varphi$ iff there is a world at which $\varphi$.

As the above scheme is an equivalence, it can be represented as a conjunction of two true implications:

(a) If it is possible that $\varphi$, then there is a world at which $\varphi$.

(b) If there is a world at which $\varphi$, then it is possible that $\varphi$.

If one postulates the existence of impossible worlds, then one could substitute for $\varphi$ a proposition that expresses impossibility, such as "A round square exists." Unfortunately, this will lead to a false consequence:

(b*) If there is a world in which a round square exists, then it is possible that a round square exists. 
To avoid this false consequence one has to add a restriction and change MR to the following:

$\left(\mathrm{MR}^{*}\right)$ It is possible that $\varphi$ iff there is a possible world in which $\varphi$ is true.

Without this restriction, one could conclude that what is impossible is also possible. Obviously in MR* a modal term appears on both sides of the scheme, making it non- reductive (Divers 2002: 69).

Since EMR is supposed to be an extension of modal realism, it should be at least as persuasive as Lewis's original theory. Unfortunately, it is far from that. Surely no Lewisian modal realist wishes to postulate true contradictions and give up a reductive analysis of modal terms. Even though it seems that EMR can handle the problem of impossibilities, the cost is too high.

The problems with EMR as a realist account of modalities might be taken as a good reason to accept ersatzism. Since, according to this account, possible worlds are identified with abstract objects, it seems that one could offer a simple extension of ersatzism containing not only possible worlds but impossible ones as well. Proposals for this kind of extension have been presented in Mares (1997), Nolan (1997) and Vander Laan (1997), among others. ${ }^{9}$ The core of the idea is quite simple. Depending on the given view of abstract possible worlds, one can extend it very naturally to include impossible worlds as well:

If one takes possible worlds as maximally consistent sets of propositions [as per (Adams 1974)], impossible worlds could be sets of propositions that are locally inconsistent and/or incomplete. Similarly, Plantingan ersatzism (worlds are particular states of affairs) or Stalnakerian ersatzism (worlds are world-natures or maximal properties) could be easily extended to impossible worlds. All hands agree that such worlds come at no great ontological or theoretical cost, once one has accepted ersatz possible worlds. After all, ersatz worlds are abstract: they account for impossibilities, not by instantiating them as Lewisian worlds do, but by representing them in some way or other. (Berto 2013)

An appropriate metaphor for a world understood as an abstract entity representing how the actual world might be is a book containing an analogous description. If one takes possible worlds as possible descriptions, then impossible worlds should be taken simply as impossible (non-maximal or inconsistent) ones. The content of such a book represents how the actual world could not be. ${ }^{10}$ In this sense, one does not have to postulate real contradictions, but merely abstract objects that represent them. Just as a sheet of paper with a drawing by Escher is not an inconsistent object, but only represents one, so the existence of abstract impossible worlds does not imply real contradictions. In this sense, if one accepts the existence of sets of propositions, postulating the existence of abstract impossible worlds does not require us to accept the existence of a new kind of entity.

\footnotetext{
${ }^{9}$ These are works in which the ersatzist approach to impossible worlds has been developed; the origins of this view might be found in Plantinga (1974).

${ }^{10}$ See (Priest 1997).
} 
Advocates of Extended Ersatzism (EE) claim that, in contrast to EMR, abstractionist accounts do not lead to the same problems as the realistic interpretation of impossible worlds. This is because such worlds are taken to be merely abstract representations of what is impossible. For this reason, ersatzism might be easily extended to include representations of impossible worlds.

That EE is ontologically less controversial as an analysis of impossible worlds does not make it a better account of modalities in general. In this case, the acceptance of abstract impossible worlds requires us to accept a similar view of merely possible worlds. The main problem with this is that, contrary to modal realism, ersatzism does not deliver a reductive analysis of modalities and treats modal terms as primitive.

Advocates of abstractionism have argued that every theory needs some primitive terms, and that it is better to operate thus than to postulate the existence of a plentitude of real possible (and impossible) worlds. ${ }^{11}$ Nevertheless, it seems that if one wishes to deliver an interesting theory of modalities in general, then one should explain, in non-circular fashion, what modal terms mean (or at least give a sufficient reason why modalities cannot be reduced).

Most importantly, there are philosophers who think that this is possible; moreover, one need not add much to original modal realism. As has been pointed out by John Divers:

[Modal realism] contains the resources for constructing books, qua sets of propositions (Lewis 1986: 185). Books, qua sets of propositions are sets of sets of genuine worlds, and inconsistent books, qua sets of inconsistent propositions, are sets of mutually disjoint sets of worlds. Inconsistent books, qua sets of propositions, are distinguished by their membership (Divers 2002: 313 , footnote 19$)$.

This appears to be an attractive solution for realists interested in an ontologically cheap analysis of impossibilities. Since impossible worlds are considered as sets, one does not have to postulate real contradictions. At the same time, this saves reductive analysis, since possible worlds are taken to be spatiotemporal objects and MR thus remains valid. Let us look more closely at this proposal.

\section{Hybrid Modal Realism}

Although the idea of constructing impossibilities out of possibilities is present in various works, ${ }^{12}$ in this paper we will focus on Hybrid Modal Realism (HMR), as defended by Francesco Berto (2010). ${ }^{13}$

The starting point for HMR is the well-known modal realist analysis of propositions, according to which propositions are identified with sets of concrete

\footnotetext{
11 See (Vander Laan 1997).

12 See (Restall 1997; Kiourti 2010: Chapter 3; Jago 2012).

13 However, we believe that at least some of the objections presented here also apply to similar constructivist accounts.
} 
possible worlds. Let the proposition [A] "It is raining" be identified with the set of worlds where it is true that it is raining; for example, $[\mathrm{A}]=\{w, v\}$. If we assume, for simplicity's sake, that the set of all possible worlds contains four elements $(U=\{w, v, s, t\}$,$) , then the proposition "It is not the case that it is raining" should$ be identified with the complement of $[\mathrm{A}]$, namely $[\neg \mathrm{A}]=\{s, t\}$. As suggested by Divers, one can construe impossible worlds in terms of sets of possible ones. Impossible worlds where both propositions are true ("It is raining and it is not the case that it is raining") should be represented by a set of sets of possible worlds, $[\mathrm{A} \& \neg \mathrm{A}]=\{\{w, v\},\{s, t\}\}$. In the same way, a different contradiction might be represented as a different set of sets. For example, if [B] "The Netherlands won the 2010 World Cup" $=\{w, s\}$ and $[\neg \mathrm{B}]$ "It is not the case that the Netherlands won the 2010 World Cup" $=\{v, t\}$, then $[\mathrm{B} \& \neg \mathrm{B}]=\{\{w, s\},\{v, t\}\}$. Since these sets contain different elements, we can say that different objects represent these contradictions.

According to Berto, thanks to this analysis one can be a modal realist and represent impossibilities. At the same time, one does not have to postulate a real contradiction, because impossible worlds are just abstract entities (sets). Moreover, the reductive analysis of modal terms is preserved, because possible worlds are considered to be concrete objects. Thanks to this, one is still entitled to assert the MR schema and does not have to claim that there is, sensu stricto, a world where such contradictions are true. In this sense, there is no bridge between acceptance of MR and the claim that contradictions are possibly true, because only for every possibility is there a spatiotemporal world where it is true. One cannot say the same about impossibilities. These are represented by sets of sets of worlds, and not by worlds as such. In this sense, HMR might be an attractive tool for a modal realist who wishes to consider impossibilities. Although it seems that HMR offers an ontologically inexpensive tool for analyzing impossibilities, it is worth asking whether one can successfully apply this strategy to solve the three aims for postulating impossible worlds mentioned earlier in this paper.

\section{Too Few Impossibilities}

The first problem with HMR was noticed by Berto himself: namely, the problem of representing impossibilities which are not conjunctions of contradictory pairs of sentences. Consider "Kate drew a round square," "10 is a prime number," "Fermat's Last Theorem is false," etc. Because it is hard to represent the above propositions as pairs of contradictory sentences and because each of them expresses an impossibility, HMR has a problem with the proper analysis of such so-called atomic impossibilities. Berto argues that, assuming that the bases for this theory are complete possible worlds, some atomic impossibilities can be reduced to a conjunction of contradictory sentences. In this sense, "Kate drew a round square" might be reduced to a set of sets of worlds in which the first is a set of worlds where it is true that Kate drew something round, and the second is a set of worlds where it is true that Kate drew a square. Although this kind of reduction works for some 
atomic impossibilities, it is hard to say how one would develop a similar analysis for many other impossibilities of the sorts listed above.

Since each possible world is a complete object (i.e. for every proposition $\mathrm{P}$ and every world $w$ either at $w$ : $\mathrm{P}$ or at $w$ : $\neg \mathrm{P}$ ), one can construct only those kinds of impossible worlds which represent contradictions but not incompleteness. If one assumes that every possible world is complete and maximal, then it is impossible that neither $\mathrm{Q}$ nor $\neg \mathrm{Q}$ is true in any possible world. If that is true, then there should be an impossible (constructed) world where neither Q nor $\neg \mathrm{Q}$ is true. Unfortunately, since each impossible world is constructed out of consistent and complete worlds, then at least $\mathrm{Q}$ or $\neg \mathrm{Q}$ has to be true in each of these worlds. This leads to an important limitation, namely, that HMR thus becomes a theory of merely one kind of impossibility, i.e., contradiction.

Moreover, if one wishes to take modal realism as a basis for a theory of impossible worlds, then one has to face the problem of representing impossibility expressed by existential claims about entities that are not part of any possible worlds. It seems that this problem affects every entity, which is novel from the point of view of modal realism. As an example of this we can take "Monads exist" or "There are transworld individuals who exist entirely in two possible worlds," etc.

\section{Counterintuitive Counterpossibles}

The second limitation of HMR is related to the problem of counterpossibles. Since the basis for HMR is Lewis's realism, one can assume that Berto also accepts analysis of counterfactuals in terms of worlds. In this case, the above problem implies difficulties in analyzing counterfactuals containing atomic impossibilities, such as:

9. If monads existed, then Leibniz would be right about metaphysics.

15. If there were individuals who exist entirely in two possible worlds, then Lewis would be right about metaphysics.

Assuming that there is no world in which the antecedents of the above counterfactuals are true, both of these counterpossibles should be vacuously true. For the reasons brought up at the very beginning of this paper, we know that philosophers of impossible worlds would like to avoid this consequence.

Moreover, it seems that there are also problems with counterpossibles containing antecedents, which can be easily represented in HMR - that is, logical contradictions, such as:

16. If it were raining and not raining at the same time, then logicians would be surprised.

If impossible worlds are identified with sets of sets of possible worlds, then worlds where it is raining and not raining at the same time can be represented by sets $\{\{w$, $s\},\{v, t\}\}$ such that the first subset represents "it is raining" and the second "it is not 
raining." Although one can represent such impossibilities in this way, it is hard to find a way to explain that counterpossible (16) is false or non-vacuously true. After all, neither $\{w, s\}$ nor $\{v, t\}$ says anything about logicians being surprised by the fact that it is raining and not raining at the same time. From a logical point of view, there is nothing impressive about it raining or not raining in a particular world. Hence, the impossible world where it is raining and not raining and where this does not surprise logicians has to be considered as one which is closer to the actual world than one in which logicians are surprised. As a consequence, (16) is false while (17) is true:

17. If it were raining and not raining at the same time, then logicians would not be surprised.

One could argue that this conclusion, although surprising, might be true. After all, a world where it is raining and not raining at the same time and where logicians are not surprised might be closer to the actual world. This might be so because it is a world which is described by the laws of logic in a consistent way. There is nothing in such a world that could be amazing or surprising to logicians. If it is true that in a world $w$ a given logic (whatever it is) is the true one, then it seems that logicians should not be surprised by the fact that reality acts according to these laws. In this sense, the world where logicians are surprised because of a given logic being true seems to be even "more" impossible than one where a different logic is true and logicians know it-just as, probably, nobody is surprised, when it comes to the actual world, that it is true that it is raining or not raining. After all, this is a simple exemplification of the law of the excluded middle.

Moreover, this world could be closer because it is one where the consequent has the same value as in the actual world, while, in the case of the world described by (16), the antecedent as well as the consequent are dissimilar to the actual world. In this sense, the world described by (17) has much more in common with the actual world than the world described by (16). Similar remarks on the problem of counterpossibles can be found in Hirsch (2009: 254, footnote 36).

The main problem with this kind of analysis is that, if it works for counterpossibles, then there is no reason why it could not work for counterfactuals in general. Consider counterfactuals such as:

18. If Mont Blanc was the highest mountain in the world, it would be higher than Mount Everest.

19. If Mont Blanc was the highest mountain in the world, it would be lower than Mount Everest.

Since in the actual world it is true that Mont Blanc is lower than Mount Everest, the world described by (19) should be, according to the above remark, more similar to the actual world than the one where Mount Blanc is the highest mountain and where it is higher than Mount Everest. This conclusion is far from what we would like to claim by using counterfactual and counterpossible reasoning. 
Although there are reasons to believe that (16) is closer to the actual world than (17), it seems that this conclusion misses the motivations for postulating impossible worlds in the first place. After all, from the point of view of the actual world, we want to admit that it would be surprising if an inconsistent state of affairs occurred, and thus one would expect that a theory based on the semantics of worlds (in this case possible as well as impossible) would explain why that is so.

The notion of similarity is without doubt one of the most puzzling elements of the analysis of counterfactuals in a framework of worlds. It is already a tricky issue for the standard Stalnaker-Lewis semantics, and becomes even trickier when impossible worlds are introduced. But the problem that we would like to point out is that when HMR is assumed, regardless of the exact notion of similarity, one cannot give a proper analysis of pairs such as (16) and (17).

\section{Alternative Theories}

The third problem is connected with an interpretation of alternative logics and metaphysics. As we mentioned at the very beginning, one of the aims of postulating impossible worlds is to enable nontrivial inferences to be represented based on the assumption that alternative accounts of logic or metaphysics are true. In this sense, we can claim that, assuming ersatzism is true, there are no spatiotemporal possible worlds, or that, assuming dialetheism is true, there are true contradictions. It seems that when it comes to this issue, the advocates of HMR face a dilemma: either (1) HMR leads to a contradiction in Lewis's original theory or (2) HMR is an insufficient tool for analyzing alternative metaphysics and logics.

As an example, let us take dialetheism, i.e. metaphysics based on paraconsistent logic, and admit that some contradictions are true (so-called dialetheia) (Priest 2006). One of the well-known examples of these is the so-called Liar sentence (L):

(L) “(L) is false."

According to dialetheism, (L) is both true and false. It seems that because dialetheism claims that there are true contradictions, it should be easy to represent them in the framework of HMR. To do so, we should assume that the "Liar's world" $\left(w_{\mathrm{L}}\right)$, i.e., the world where $(\mathrm{L})$ is both true and false, is represented by a set of sets of possible worlds, such that the first subset is one where $[\mathrm{P}]$ " $(\mathrm{L})$ is false" is true, and the second where $[\neg \mathrm{P}]$ " $(\mathrm{L})$ is true" is true. So $w_{\mathrm{L}}$ is identified with $\mathrm{P} \& \neg \mathrm{P}$. Let us assume again that the ontological universe of possible worlds contains only four elements $(U=\{w, v, s, t\}$,$) . If we identify [\mathrm{P}]$ with $\{w, t\},[\neg \mathrm{P}]$ should be identified with $\{v, s\}$. As a result we obtain $w_{\mathrm{L}}$, identified with $\{\{w, t\},\{v, s\}\}$.

Although this looks very similar to any other case of a contradiction, this special type of dialetheia, which should be analyzed in terms of merely possible worlds, leads to unwelcome consequences, because, based on the truth conditions for the proposition, the truth of $[\mathrm{P}]$ implies the falsehood of $[\mathrm{P}]$ (truth of $[\neg \mathrm{P}]$ ) and, vice versa, the truth of $[\neg \mathrm{P}]$ implies the falsehood of $[\neg \mathrm{P}]$. This leads to the conclusion that $[\mathrm{P}]$ is true iff $[\neg \mathrm{P}]$ is true. As a result, in every world where $[\mathrm{P}]$ is true, $[\neg \mathrm{P}]$ is true as well. Therefore, from the actual world's point of view, it is true that in every 
possible world $(w, v, s, t)$ it is true that $\mathrm{P} \& \neg \mathrm{P}$. In this sense Berto's account does not avoid the problem which arose with regard to Yagisawa's account. In both cases a contradiction in an impossible world spills out into a contradiction in the actual world.

One can reply to this problem simply by pointing out that it is based on the false assumption that there are spatiotemporal worlds where $\mathrm{P} \& \neg \mathrm{P}$ is true. After all, according to Lewisian modal realism, there is no such world. It is hard to deny this point. Nevertheless, although in this sense HMR does not lead to a contradiction in the actual world, it is hard to see how one can perform an analysis of (L) based on HMR in any other way. After all, dialetheism claims that (L) is a true contradiction, and as such it should, seemingly, fit within the apparatus of HMR.

Obviously, the Liar's paradox is one of the greatest philosophical problems, one which has puzzled philosophers for thousands of years. Nevertheless, one can assume that if there is an account of impossibilities represented by sets of inconsistent sets of possible worlds, then one should be able to use it to represent the status of the Liar sentence ascribed to it by advocates of dialetheism. Otherwise, we should find a reason one can perform an analysis for some contradictions and not others. As we mentioned earlier, one possible reason is that HMR is based on modal realism and thus impossible worlds might be constructed only of the spatiotemporal worlds postulated by this account. Since there is no world where contradictions are true, then there is no world where $\mathrm{P} \& \neg \mathrm{P}$; therefore one cannot construct $w_{\mathrm{L}}$. This is true, but it places an important limitation on what one can represent as an impossible.

Dialetheism is not the only theory which is difficult to represent in terms of HMR. Due to the already mentioned problems with the representation of impossibilities such as "The law of the excluded middle is false" or "Transworld individuals exist," any proper analysis of the theories for which these claims hold true will be unclear. This shows how problems with representations of impossibilities infect other areas of philosophical investigations in which some philosophers would like to postulate impossible worlds.

Hybrid Modal Realism is an interesting and ambitious way of dealing with impossibilities, mostly because its aim is to preserve the theoretical values of both alternative views (realism in the case of possible, ersatzism in the case of impossible worlds). On one hand it wants to deliver a reductive analysis of modalities; on the other, it requires no highly controversial real contradictions. In this sense it might be an attractive tool for modal realists who are interested in dealing with impossibilities. After all, one does not have to add very much to Lewis's original view to deal with impossibilities (at least some of them). Nevertheless, HMR has serious limitations: (1) it cannot represent various impossibilities or differentiate between them, (2) its analysis of counterpossibles leads to conclusions which go against our intuitions, (3) it is insufficient when it comes to analyses of alternative accounts of metaphysics and logic.

Acknowledgments This material has been presented at "Ontoconf2013" (University of Warsaw, 2013) and "Issues in the Impossible Worlds" Workshops (Slovak Academy of Sciences, 2013). I am grateful to 
Francesco Berto, Arkadiusz Chrudzimski, John Divers, Rafał Urbaniak, and the anonymous Reviewer. Their questions and comments helped me to improve the previous version of this text. This material is based on work supported by the Foundation for Polish Science, Program MASTER (directed by Tadeusz Szubka).

Open Access This article is distributed under the terms of the Creative Commons Attribution License which permits any use, distribution, and reproduction in any medium, provided the original author(s) and the source are credited.

\section{References}

Adams RM (1974) Theories of Actuality. Noûs 8:211-231

Berto F (2010) Impossible worlds and propositions: against the parity thesis. The Philosophical Quarterly 60(240):471-486

Berto F (2013) Impossible worlds. In: Zalta EN (ed) The stanford encyclopedia of philosophy. http:// plato.stanford.edu/entries/impossible-worlds

Brandom R, Rescher N (1980) The logic of inconsistency: a study in non-standard possible worlds semantics and ontology. Basil Blackwell, Oxford

Divers J (2002) Possible worlds. Routledge, London

Hirsch E (2009) Ontology and alternative languages. In: Chalmers D, Manley D, Wasserman R (eds) Metametaphysics: new essays on the foundations of ontology. Oxford University Press, Oxford

Jago M (2012) Constructing worlds. Synthese 189(1):59-74

Kiourti I (2010) Real impossible worlds: the bounds of possibility. Ph.D. Dissertation, University of St. Andrews

Lewis D (1973) Counterfactuals. Blackwell, Oxford

Lewis D (1986) On the plurality of worlds. Blackwell, Oxford

Lewis D (2004) Letters to Beall and Priest. In: Priest G, Beall JC, Armour-Garb B (eds) The law of noncontradiction: new philosophical essays. Oxford University Press, Oxford

Mares E (1997) Who's afraid of impossible worlds? Notre Dame Journal of Formal Logic 38(1997):516-526

Nolan D (1997) Impossible worlds: modest approach. Notre Dame Journal of Formal Logic 38(4):535-572

Nolan D (2013) Impossible worlds. Philosophy Compass 8:360-372

Plantinga A (1974) The nature of necessity. Clarendon Press, Oxford

Priest G (1992) What is a non-normal world? Logique et Anal 35:291-302

Priest G (1997) Sylvan's box: a short story and ten morals. Notre Dame Journal of Formal Logic 38(1997):573-582

Priest G (2006) In contradiction. Oxford University Press, Oxford

Restall G (1997) Ways things can't be. Notre Dame Journal of Formal Logic 38(1997):583-595

Sendłak M (2015) Alternative frameworks and counterpossibles. Grazer Philosophische Studien (forthcoming)

Stalnaker R (1968) A theory of conditionals. In: Rescher N (ed) Studies in logical theory. Blackwell, Oxford, pp 98-112

Vander Laan D (1997) The ontology of impossible worlds. Notre Dame Journal of Formal Logic. 38(4):597-620

Yagisawa T (1988) Beyond possible worlds. Philos Stud 53:175-204 